يُوهشهاى زنتيك گياهى / جلد / / شماره

تجزيه مولكولى تنوع و روابط زنتيكى زنوتيبهاى بومى جو بر اساس نشانكرهاى ريزماهواره

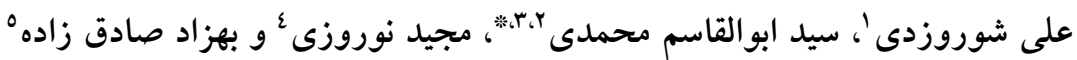

1- دانش آموخته كارشناسى ارشد، گروه بهنزادى و بيو تكنولوزى گياهى، دانشكده كشاورزى دانشگاه تبريز، تبريز

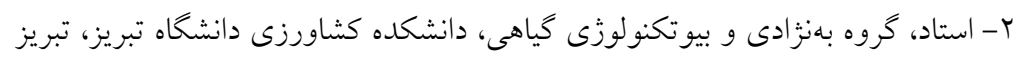

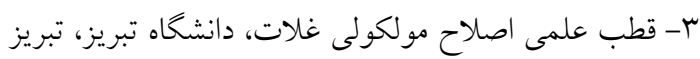

ع- استاديار، كروه بهنزادى و بيو تكنولوزى گياهى، دانشكده كشاورزى دانشخاه تبريز، تبريز

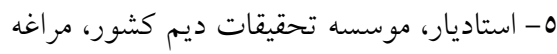

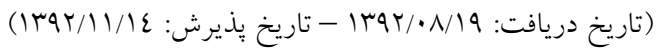

زنوتيبهاى بومى بهدليل تطابق و سازكارى با شرايط محيطى مختلف، ذخاير زنتيكى با ارزشى براى افزايش تنوع

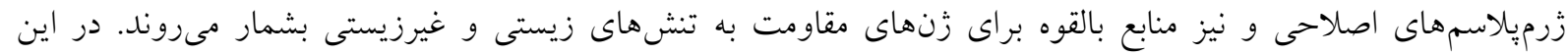

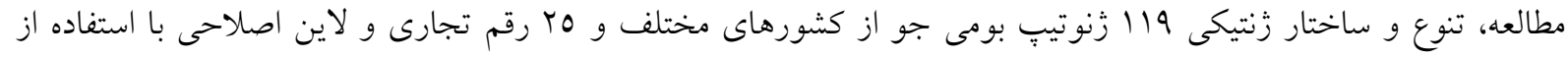

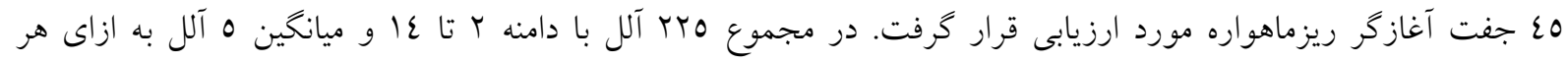

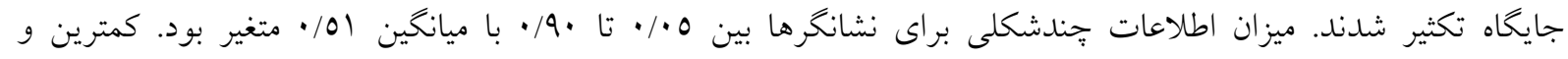

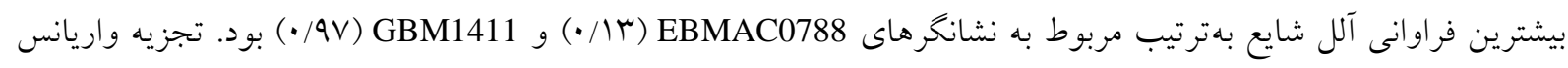

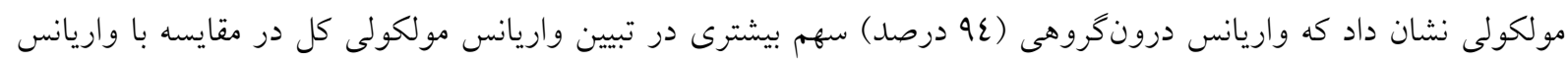

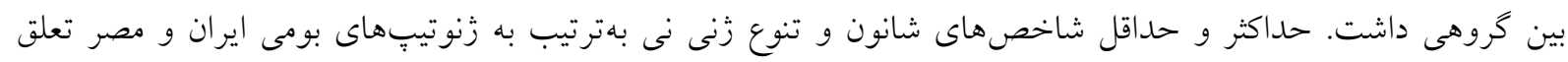

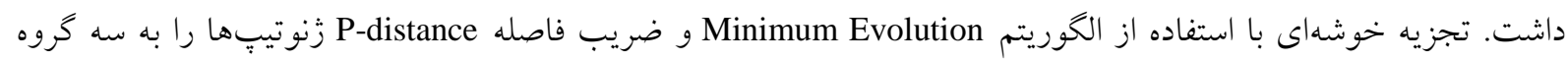

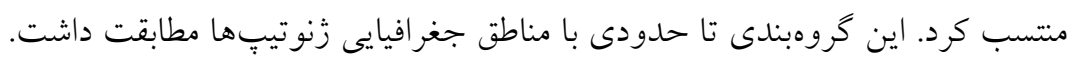
وازگ كان كليدى: تنوع زنتيكى، زرميلاسم، زنوتيبهاى بومى جو، ساختار جمعيت 
2010) با بررسى روابط زنتيكى كا زنوتيب جو با استفاده مقدمه - م - م

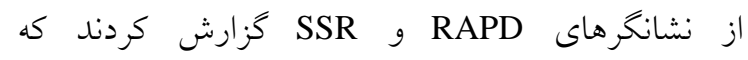
نشانكرهاى SSR تنوع بالايى را نسبت به نشانكرهاى

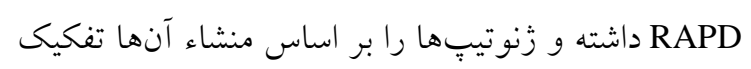
مى كنند. ابراهيمى و همكاران (Ebrahimi et al., 2010) در بررسى تنوع زنتيكى سل لنمونه جو ايران از دو كونه Hordeum vulgare جفت نشانكر ريزماهواره، آنها را به سه كروه منتس كردند. گروه اول شامل نمونههايى از هر دو خونه vulgare كروهاى دوم و سوم بهترتيب شامل نمونههايى از vulgare با استفاده از 19 جفت آغازگر (Heidari et al., 2011)

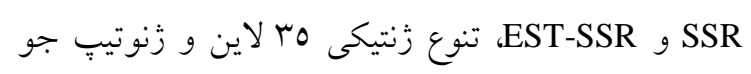

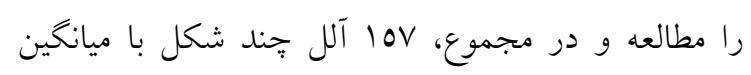

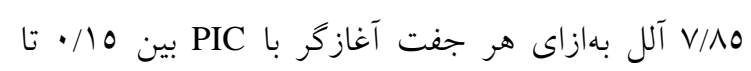

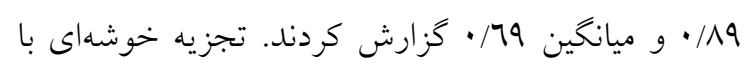

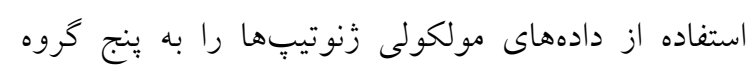
Ganjekhanloo et ( متسب كرد. كنج خانلو و همكاران

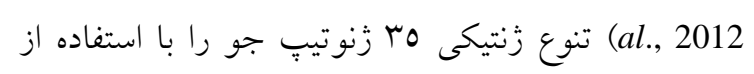

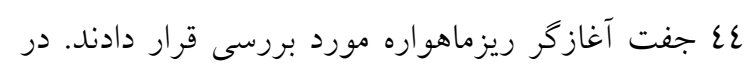

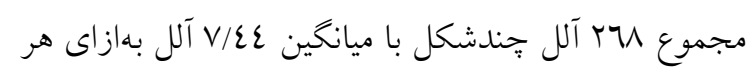

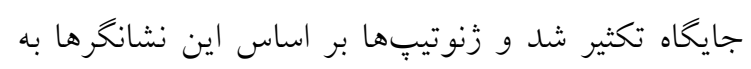

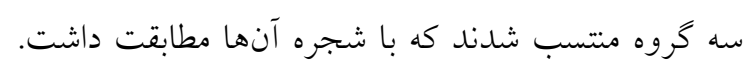

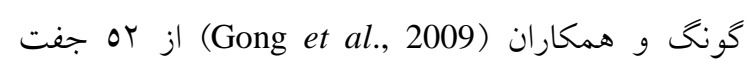

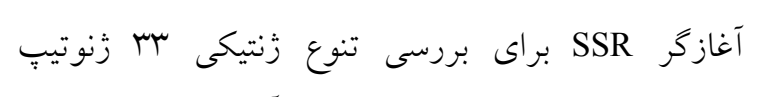

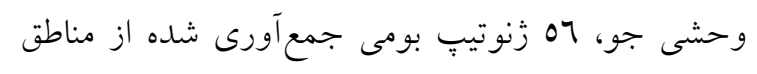

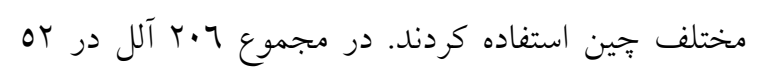

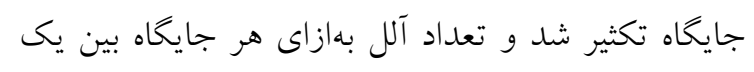

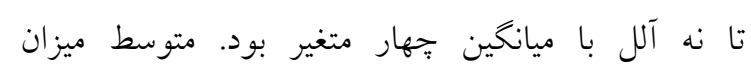

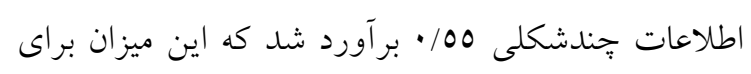

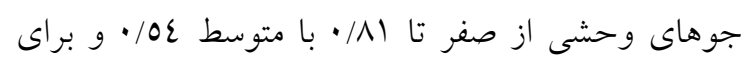

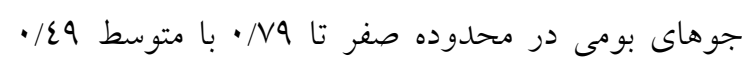

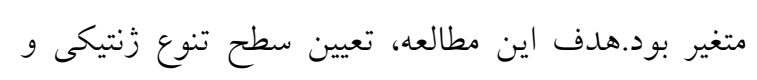
جو يكى از مهمترين گياهان زراعى دنيا محسوب مىشود

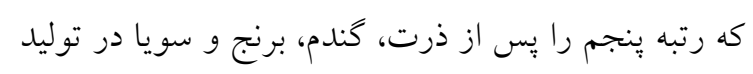

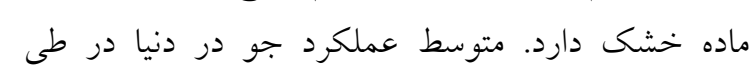

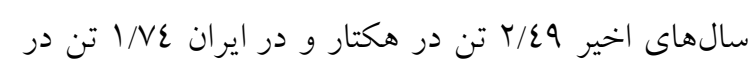
هكتار بوده است (FAO, 2013). در سالهاى اخير بهعلت استفاده از ارقام اصلاح شده و

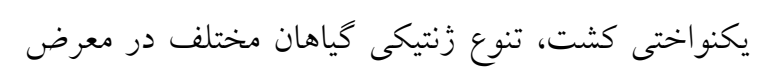

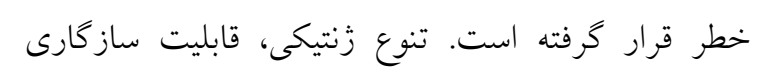

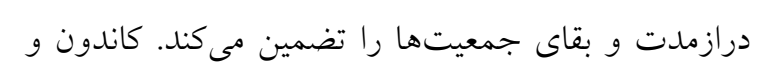

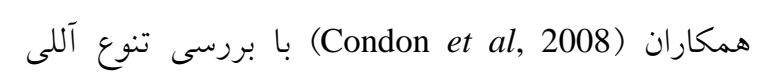
ارقام جو كشت شده در طى سالهاى 1910 اتا 1991 با استفاده از نشانخرهاى ريزماهواره نشان دادند كه ميزان

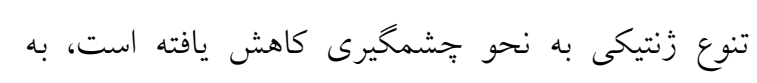

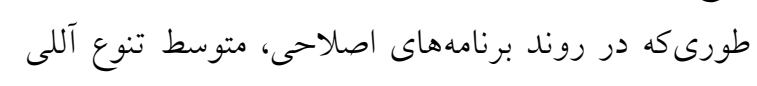

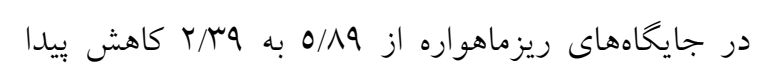

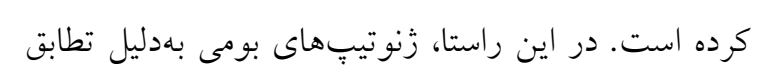

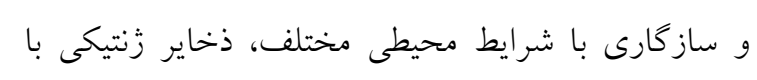

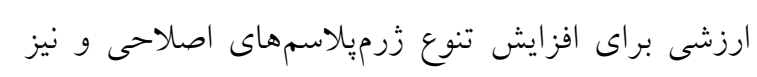

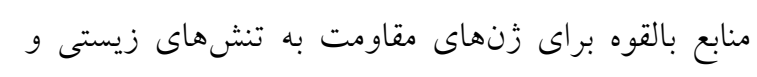
غيرزيستى مى باشند (Brush and Meng, 1998). بررسى تنوع و تعيين روابط زنتيكى افراد در كياهان

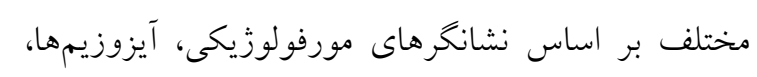

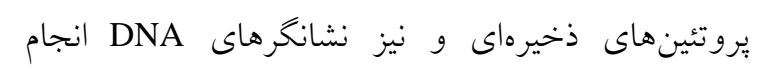

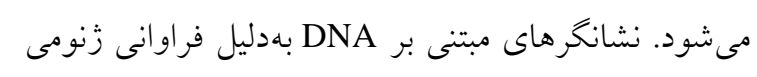

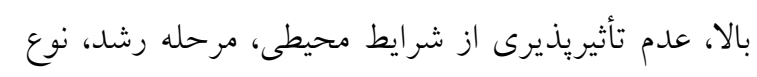

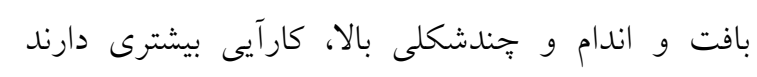
SSR Joshi et al., 1999)

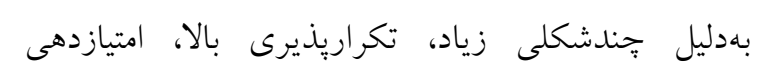

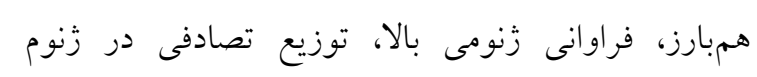

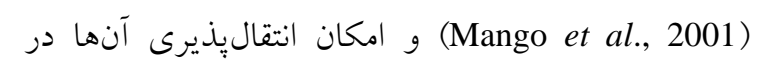
كونهها و جنس هاى خويشاوند (Wang et al., 2005)

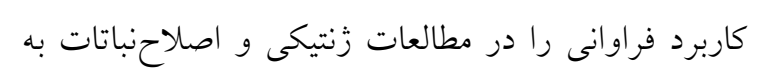

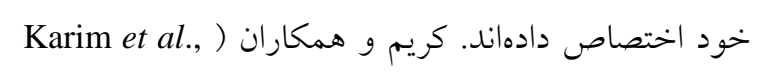


تعيين قدرت تمايز نشانخرها، بِارامترهاى ميزان اطلاعات

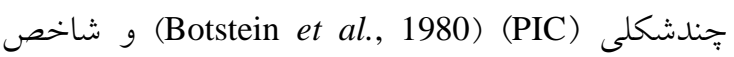
تنوع زنى نى (Nei, 1973) (H) با استفاده از فرمولهاى زير توسط نرم|فزار 3.25 Liu and ) PowerMarker V. (Muse, 2005
$\mathrm{PIC}=1-\sum p_{\mathrm{i}}^{2}-2 \sum \mathrm{p}_{\mathrm{i}}^{2} \mathrm{p}_{\mathrm{j}}^{2}$
رابطه (1)
$\mathrm{H}=1-\sum \mathrm{p}_{\mathrm{i}}^{2}$
رابطه (Y)

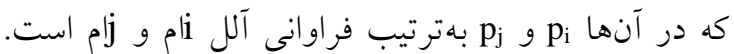

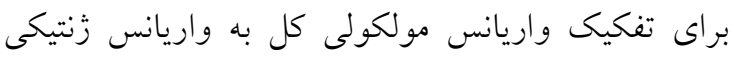
درون و بين كروهها از تجزيه واريانس مولكولى لفيلى با نرم|فزار (Excoffier et al., 1992.) (AMOVA) (Peakall and Smouse, 2006) GenALEx V. 6.4 استفاده شد. علاوه بر اين، تنوع درون گروهها بر اساس

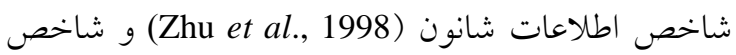

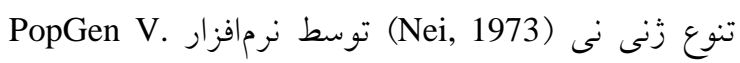
(Yeh et al., 1997) 1.32 زنوتي״ها با استفاده از تجزيه خوشهاى بر اساس الكوريتم pinimum Evolution MEGA انجام شد. دندروكرام با استفاده از نرمافزارهاى فاصله

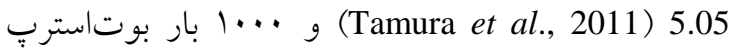
رسم كرديد. تجزيه به بردارهاى اصلى بهعنوان روش

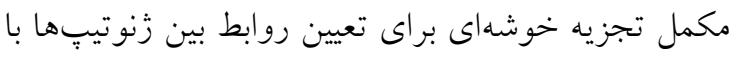

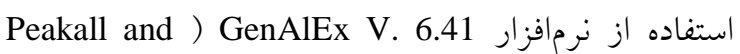

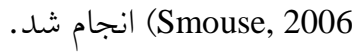

\section{نتايج و بحث}

جندشكلى نشانگرهاى ريزماهواره: از عج جفت آغازكر ريزماهواره مورد بررسى از نوع GBM، BMAC، عo SCSSR و HVM EBMAG ،BMAG ،EBMAC جفت آغازكر الكَى نوارى جِندشكلى در زنوتيِهاى مورد مطالعه ايجاد كردند. شكل ا الكوى نوارى حاصل از

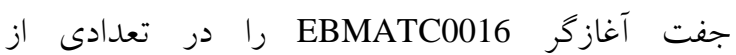

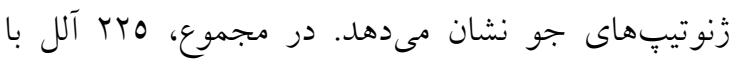

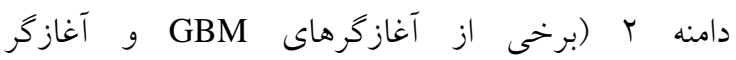
(SCSSR25538

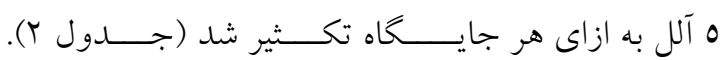

ساختار جمعيت زنوتيب بومى جو كشورهاى مختلف با

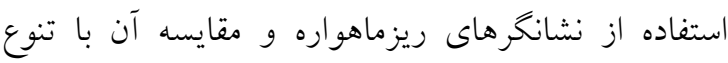
تعدادى از ارقام تجارى و لاين اصلاحى بود.

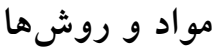

مواد كياهى مورد مطالعه، شامل 79 زنوتيِّ بومى جو

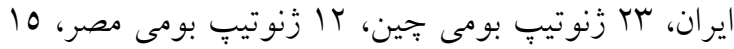
زنوتيبٍ بومى از ساير كشورها، 9 لاين بيشرفته اصلاحى و 17 رقم تجارى بود كه از موسسه تحقيقات ديم كشور

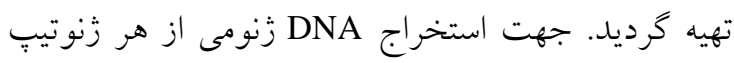
10 بذر در كلخانه كشت و نمونهها در مرحله جنا بند بركى بهصورت بالك از هر زنوتيب برداشت شدند. استخراج (Saghi-Maroof et al.,1984) CTAB به روش DNA انجام و كميت و كيفيت نمونههاى DNA با استفاده از

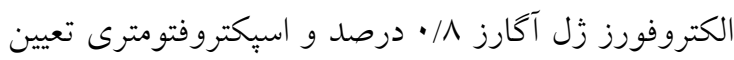

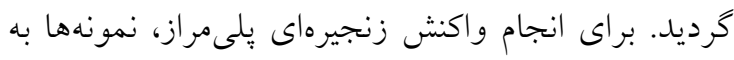

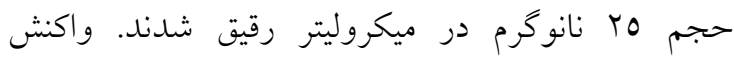

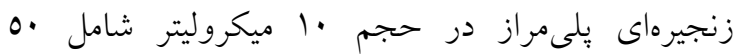

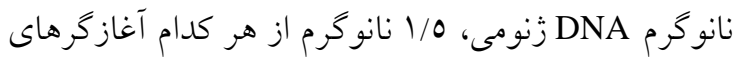
بيشرو و بسرو، كلريد منيزيوم با غلظت r ميلى مولار، مخلوط نوكلئوتيدها با غلظت r ميلى مولار و 0 واحد

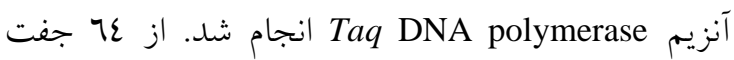
آغازگر SSR جو براى ارزيابى افراد مورد مطالعه استفاده

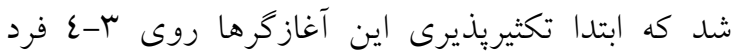
بهطور تصادفى بررسى و شرايط بهينه براى آنها تعيين كرديد. در جدول ا، جايگاه كروموزومى و دماى اتصال آغازگرهاى مورد استفاده آورده شده است. تفكيك محصولات تكثيرى توسط زل بلى آكريلاميد ع درصد با ضخامت ץ/· ميلىمتر و در دستخاه زلاسكن

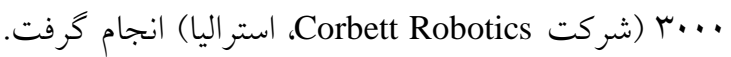
در اين سيستم آشكارسازى بر اساس رنشعآميزى اتيديومبرمايد و توسط ليزر صورت مى خيرد. الكوى نوارى

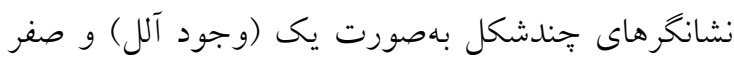

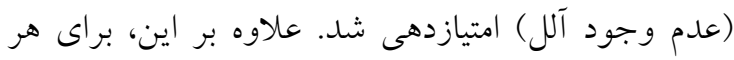

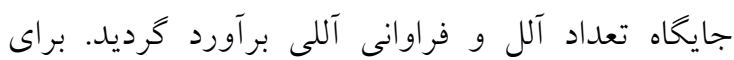




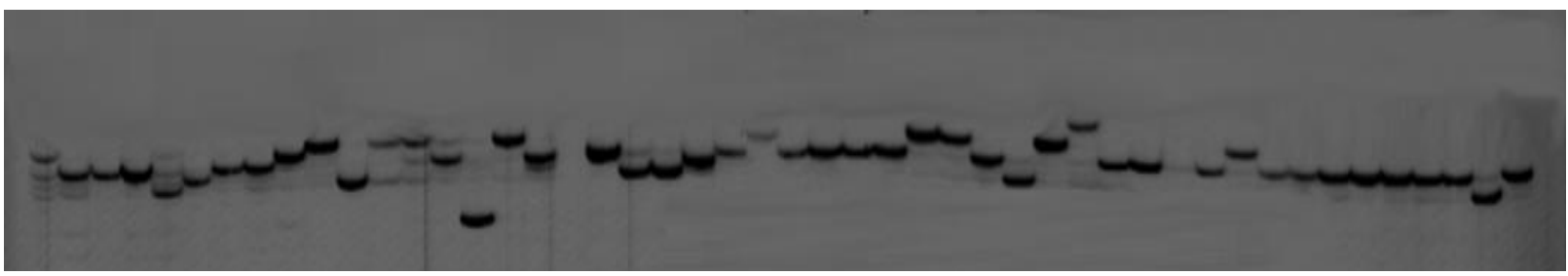

شكل 1- الكوى نوارى نشانگر EBMATC0016 در تعدادى از زنوتيبهاى بومى جو ايران

Figure 1. Banding pattern of microsatellite marker EBMAC679 in some of the Iranian barley genotypes

$$
\text { جدول ا- مشخصات آغازكرهاى ريزماهواره جو مورد استفاده در واكنش زنجيرهاى بلى مراز }
$$

Table 1. The characteristics of microsatellite primers used in polymerase chain reaction (PCR)

\begin{tabular}{|c|c|c|c|c|c|}
\hline $\begin{array}{c}\text { نام نشانكر } \\
\text { Marker name }\end{array}$ & $\begin{array}{c}\text { كروموزوم } \\
\text { Choromosome }\end{array}$ & $\begin{array}{c}\text { دماى اتصال } \\
\text { Annealing } \\
\text { Temperature }\left({ }^{\circ} \mathrm{C}\right)\end{array}$ & $\begin{array}{c}\text { نام نشانگر } \\
\text { Marker name }\end{array}$ & $\begin{array}{c}\text { كروموزوم } \\
\text { Choromosome }\end{array}$ & $\begin{array}{c}\text { دماى اتصال } \\
\text { Annealing } \\
\text { Temperature }\left({ }^{\circ} \mathrm{C}\right)\end{array}$ \\
\hline TACMD & $4 \mathrm{H}$ & $\mathrm{E}$ & GBM1411 & $1 \mathrm{H}$ & $\mathrm{F} / 60 *$ \\
\hline HVBAMY & $4 \mathrm{H} / 5 \mathrm{H}$ & $\mathrm{F} / 53$ & GBM1480 & $1 \mathrm{H}$ & $\mathrm{F} / 60$ \\
\hline GBM1295 & $5 \mathrm{H}$ & $\mathrm{F} / 60$ & GBM1487 & $1 \mathrm{H}$ & $\mathrm{F} / 60$ \\
\hline GBM5028 & $5 \mathrm{H}$ & $\mathrm{F} / 60$ & HVM63 & $1 \mathrm{H} / 2 \mathrm{H}$ & $\mathrm{E}^{* *}$ \\
\hline SCSSR10148 & $5 \mathrm{H}$ & $\mathrm{F}$ & BMAG0813 & $2 \mathrm{H}$ & $\mathrm{E}$ \\
\hline BMAC0163 & $5 \mathrm{H}$ & $\mathrm{F}$ & BMAG378 & $2 \mathrm{H}$ & $\mathrm{E}$ \\
\hline GBM1325 & $5 \mathrm{H}$ & $\mathrm{F} / 60$ & GBM1149 & $2 \mathrm{H}$ & $\mathrm{F} / 60$ \\
\hline GBMS141 & $5 \mathrm{H} / 7 \mathrm{H}$ & $\mathrm{E} / 53$ & GBM1251 & 2 & $\mathrm{~F} / 60$ \\
\hline BMAC0282 & $5 \mathrm{H} / 7 \mathrm{H}$ & $\mathrm{E}$ & GBM1408 & $2 \mathrm{H}$ & $\mathrm{F} / 60$ \\
\hline GBM1075 & $6 \mathrm{H}$ & $\mathrm{F} / 60$ & SCSRR12344 & $2 \mathrm{H}$ & $\mathrm{E}$ \\
\hline GBM1267 & $6 \mathrm{H}$ & $\mathrm{F} / 60$ & SCSSR10226 & $2 \mathrm{H}$ & $\mathrm{F}$ \\
\hline GBM1276 & $6 \mathrm{H}$ & $\mathrm{F} / 60$ & ВMAC0209 & $3 \mathrm{H}$ & $\mathrm{F} / 58$ \\
\hline GBM1404 & $6 \mathrm{H}$ & $\mathrm{F} / 60$ & BMAG0013 & $3 \mathrm{H}$ & $\mathrm{F}$ \\
\hline HVM74 & $6 \mathrm{H}$ & $\mathrm{A}$ & EBMAC0871 & $3 \mathrm{H}$ & $\mathrm{E}$ \\
\hline BMAG0807 & $6 \mathrm{H} / 7 \mathrm{H}$ & $\mathrm{E}$ & GBM 1450 & $3 \mathrm{H}$ & $\mathrm{F} / 60$ \\
\hline BMAG0174 & $6 \mathrm{H} / 7 \mathrm{H}$ & $\mathrm{F}$ & GBM1405 & $3 \mathrm{H}$ & $\mathrm{F} / 60$ \\
\hline BMAC0167 & $7 \mathrm{H}$ & $\mathrm{E}$ & GMS116 & $3 \mathrm{H}$ & $\mathrm{E}$ \\
\hline BMAG0507 & $7 \mathrm{H}$ & $\mathrm{F}$ & Hv13GEIII & $3 \mathrm{H}$ & $\mathrm{F}$ \\
\hline BMAG0516 & $7 \mathrm{H}$ & $\mathrm{F} / 55$ & SCSSR 25538 & $3 \mathrm{H}$ & $\mathrm{E}$ \\
\hline EBMAG0794 & $7 \mathrm{H}$ & $\mathrm{F} / 49$ & GBM1300 & $3 \mathrm{H}$ & $\mathrm{F} / 60$ \\
\hline ЕВMАТC0016 & $7 \mathrm{H}$ & $57 / \mathrm{E}$ & GBM1420 & $3 \mathrm{H}$ & $\mathrm{F}$ \\
\hline GBM1116 & $7 \mathrm{H}$ & $\mathrm{F} / 60$ & HVM70 & $3 \mathrm{H}$ & A \\
\hline GBM1297 & $7 \mathrm{H}$ & $\mathrm{F} / 60$ & BMAC0310 & $4 \mathrm{H}$ & $\mathrm{E}$ \\
\hline GBM1413 & $7 \mathrm{H}$ & $\mathrm{E}$ & BMAG0375 & $4 \mathrm{H}$ & $\mathrm{E}$ \\
\hline GBM1419 & $7 \mathrm{H}$ & $\mathrm{F} / 60$ & EBMAC0635 & $4 \mathrm{H}$ & $\mathrm{F}$ \\
\hline GBM1428 & $7 \mathrm{H}$ & $\mathrm{F} / 60$ & EBMAC0788 & $4 \mathrm{H}$ & $\mathrm{F}$ \\
\hline GMS046 & $7 \mathrm{H}$ & $\mathrm{E}$ & EBMAC0906 & $4 \mathrm{H}$ & $\mathrm{E}$ \\
\hline BMAC0064 & $7 \mathrm{H}$ & $\mathrm{E} / 58$ & GBM1422 & $4 \mathrm{H}$ & $\mathrm{F} / 60$ \\
\hline BMAG0109 & $7 \mathrm{H}$ & $\mathrm{F}$ & GBM1482 & $4 \mathrm{H}$ & $\mathrm{F} / 60$ \\
\hline BMAG0135 & $7 \mathrm{H}$ & $\mathrm{E}$ & BMAC0084 & $4 \mathrm{H}$ & $\mathrm{F} / 54$ \\
\hline GBM1494 & $7 \mathrm{H}$ & $\mathrm{F} / 60$ & BMAC0181 & $4 \mathrm{H}$ & $\mathrm{E} / 58$ \\
\hline GBM1552 & - & $\mathrm{F} / 60$ & GBM1364 & $4 \mathrm{H}$ & $\mathrm{F}$ \\
\hline
\end{tabular}

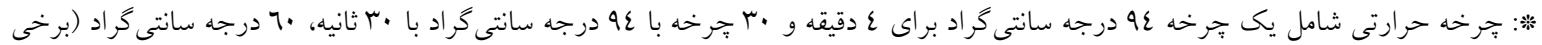

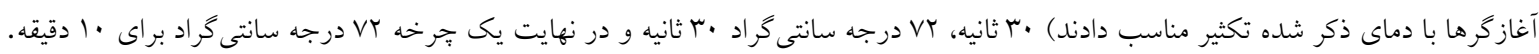

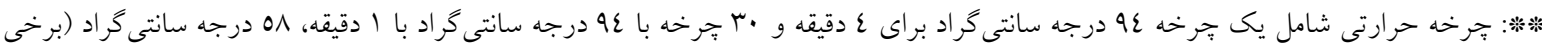

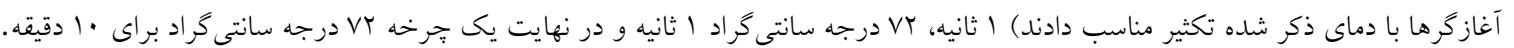

* Thermal cycling conditions included denaturation at $94^{\circ} \mathrm{C}$ for 4 min and 30 cycle at $94^{\circ} \mathrm{C}$ for $30 \mathrm{sec}$, annealing at $60^{\circ} \mathrm{C}$ for $30 \mathrm{sec}$ and finaly cycle at $72^{\circ} \mathrm{C}$ for $10 \mathrm{~min}$.

** Thermal cycling conditions included denaturation at $94^{\circ} \mathrm{C}$ for $4 \mathrm{~min}$ and 30 cycle at $94^{\circ} \mathrm{C}$ for $1 \mathrm{~min}$, annealing at $58^{\circ} \mathrm{C}$ for $1 \mathrm{sec}, 72^{\circ} \mathrm{C}$ for $1 \mathrm{sec}$ and finaly one cycle at $72^{\circ} \mathrm{C}$ for $10 \mathrm{~min}$. 


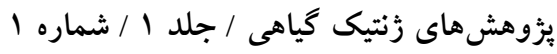

$$
\text { جدول r- ميزان اطلاعات جندشكلى (PIC)، هتروزيخوسى مشاهده شده، تنوع زنى، تعداد آل و فراوانى آلل شايع براى نشانگرهاى ريزماهواره جو }
$$

Table 2. The polymorphism information content (PIC) value, amount of heterozygosity, gene diversity, allele

\begin{tabular}{|c|c|c|c|c|c|}
\hline نشانگر & $\begin{array}{c}\text { فراوانى آلل شايع } \\
\text { Frequency of more } \\
\text { common allele }\end{array}$ & $\begin{array}{c}\text { تعداد آلل } \\
\text { Allele No. }\end{array}$ & $\begin{array}{c}\text { تنوع زنى } \\
\text { Gene diversity }\end{array}$ & هتروزيخوسى 1 Heterozygosity & $\begin{array}{c}\text { محتو اى اطلاعات } \\
\text { PIC } \\
\text { PIC }\end{array}$ \\
\hline GBM1482 & 0.44 & 6.00 & 0.72 & 0.00 & 0.68 \\
\hline SCSSR10148 & 0.45 & 8.00 & 0.74 & 0.00 & 0.71 \\
\hline GMS116 & 0.18 & 10.00 & 0.88 & 0.00 & 0.86 \\
\hline BMAC0310 & 0.39 & 8.00 & 0.77 & 0.00 & 0.74 \\
\hline EBMAG0794 & 0.80 & 3.00 & 0.34 & 0.00 & 0.31 \\
\hline GBM1413 & 0.41 & 6.00 & 0.74 & 0.00 & 0.75 \\
\hline EBMAC0906 & 0.29 & 8.00 & 0.79 & 0.00 & 0.76 \\
\hline EBMATC0016 & 0.22 & 11.00 & 0.84 & 0.06 & 0.83 \\
\hline GBMS141 & 0.23 & 10.00 & 0.85 & 0.00 & 0.84 \\
\hline HVM74 & 0.22 & 10.00 & 0.86 & 0.00 & 0.84 \\
\hline BMAG0507 & 0.15 & 14.00 & 0.90 & 0.00 & 0.89 \\
\hline BMAG0516 & 0.29 & 8.00 & 0.83 & 0.00 & 0.80 \\
\hline BMAG0807 & 0.63 & 5.00 & 0.55 & 0.00 & 0.50 \\
\hline BMAG0813 & 0.31 & 9.00 & 0.81 & 0.01 & 0.79 \\
\hline EBMAC0635 & 0.30 & 11.00 & 0.84 & 0.07 & 0.82 \\
\hline EBMAC0788 & 0.13 & 12.00 & 0.91 & 0.01 & 0.90 \\
\hline EBMAC0871 & 0.23 & 8.00 & 0.84 & 0.00 & 0.82 \\
\hline GBM1267 & 0.84 & 2.00 & 0.27 & 0.00 & 0.24 \\
\hline GBM1251 & 0.63 & 3.00 & 0.50 & 0.00 & 0.43 \\
\hline GBM1075 & 0.65 & 3.00 & 0.50 & 0.00 & 0.44 \\
\hline BMAG0375 & 0.50 & 3.00 & 0.63 & 0.00 & 0.56 \\
\hline GMS046 & 0.70 & 3.00 & 0.47 & 0.00 & 0.42 \\
\hline GBM5028 & 0.60 & 2.00 & 0.48 & 0.00 & 0.37 \\
\hline GBM1419 & 0.94 & 3.00 & 0.11 & 0.01 & 0.11 \\
\hline SCSSR25538 & 0.81 & 2.00 & 0.31 & 0.00 & 0.26 \\
\hline BMAC0167 & 0.55 & 3.00 & 0.56 & 0.00 & 0.48 \\
\hline BMAC0209 & 0.36 & 7.00 & 0.74 & 0.00 & 0.70 \\
\hline GBM1411 & 0.97 & 2.00 & 0.06 & 0.00 & 0.05 \\
\hline GBM1405 & 0.58 & 3.00 & 0.57 & 0.02 & 0.51 \\
\hline GBM1404 & 0.96 & 2.00 & 0.08 & 0.00 & 0.08 \\
\hline GBM1297 & 0.93 & 2.00 & 0.13 & 0.00 & 0.12 \\
\hline SCSRR12344 & 0.65 & 3.00 & 0.52 & 0.00 & 0.46 \\
\hline HVI3 & 0.67 & 3.00 & 0.48 & 0.00 & 0.42 \\
\hline GBM1552 & 0.84 & 2.00 & 0.26 & 0.13 & 0.23 \\
\hline GBM 1450 & 0.47 & 3.00 & 0.57 & 0.00 & 0.48 \\
\hline GBM1480 & 0.76 & 2.00 & 0.37 & 0.00 & 0.30 \\
\hline GBM1408 & 0.94 & 2.00 & 0.12 & 0.00 & 0.11 \\
\hline GBM1422 & 0.56 & 4.00 & 0.61 & 0.00 & 0.55 \\
\hline GBM1276 & 0.62 & 3.00 & 0.53 & 0.00 & 0.47 \\
\hline GBM1295 & 0.72 & 2.00 & 0.40 & 0.00 & 0.32 \\
\hline GBM1428 & 0.56 & 2.00 & 0.49 & 0.00 & 0.37 \\
\hline HVBAMY & 0.57 & 3.00 & 0.58 & 0.00 & 0.51 \\
\hline BMAG0013 & 0.35 & 6.00 & 0.72 & 0.00 & 0.67 \\
\hline GBM1149 & 0.90 & 2.00 & 0.19 & 0.00 & 0.17 \\
\hline GBM1116 & 0.86 & 2.00 & 0.25 & 0.00 & 0.22 \\
\hline ميانگين (Mean) & 0.56 & 5.02 & 0.55 & 0.01 & 0.51 \\
\hline
\end{tabular}
No. and frequency of more common allele for SSR markers in relation to barley genotypes 
Kadri et ) نشانخر مورد استفاده است. كادرى و مكاران (al., 2002

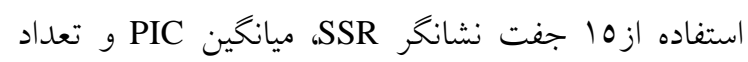

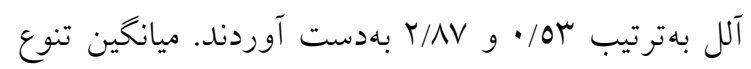

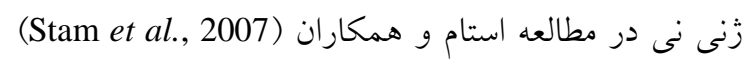

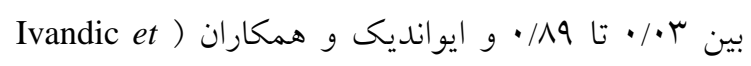

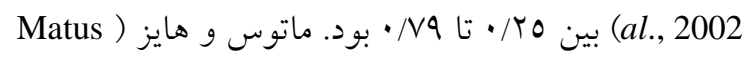

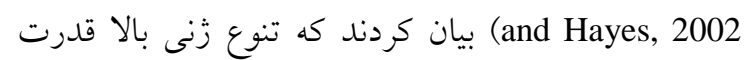
بالاى نشانكرها را در تشخيص و تفكيك دقيق زنوتيبها

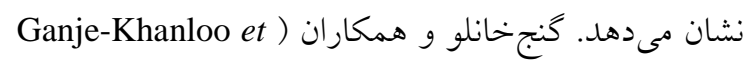
(al., 2012

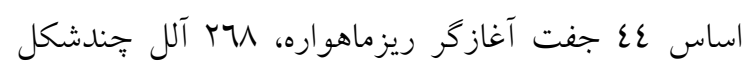
با ميانكين ع/ع آلل بهازاى هر جايگاه تكثير كردند.

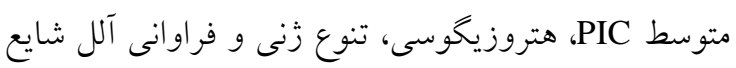

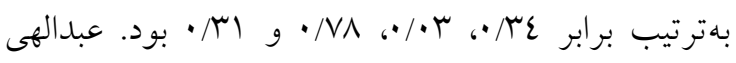

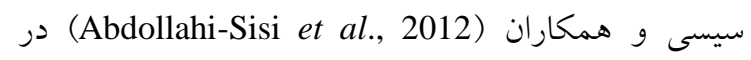

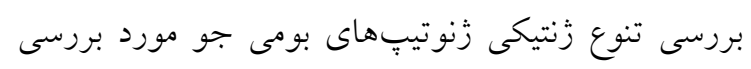

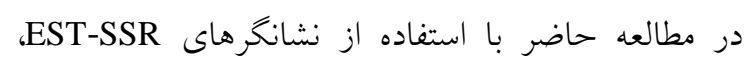

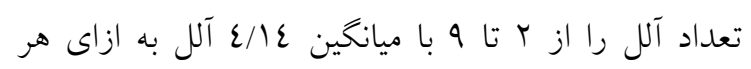

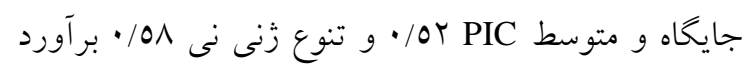

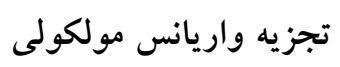

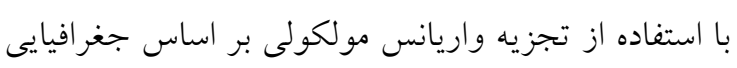

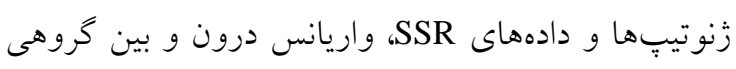

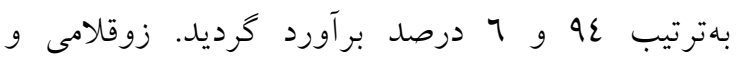

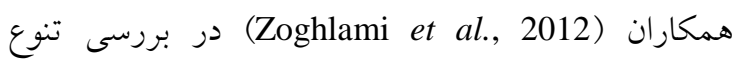

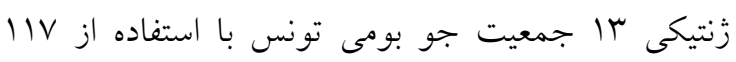

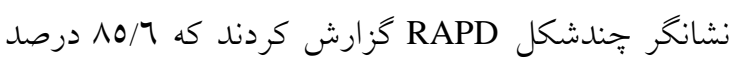
از واريانس كل توسط واريانس درون جمعيتها تبيين مىشود. كاندمير و همكاران (Kandemir et al., 2010) نيز در بررسى تنوع زنتيكى زنوتيبهاى جو، بيشترين

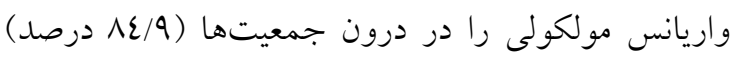
نسبت به بين جمعيتها برآورد كردند. عابد و همكاران 119 در بررسى تنوع زنتيكى (Abede et al., 2012)
نشانگرهاى كروموزومهاى 1H با جهار و ميانخين دو و

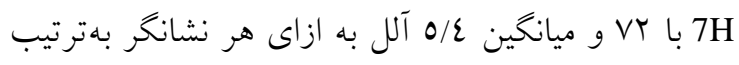

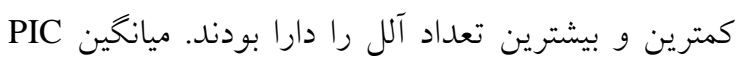
برابر آغازكرهاى GBM1411 و و EBMAC0788 بهدست آمد.

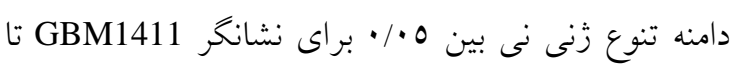

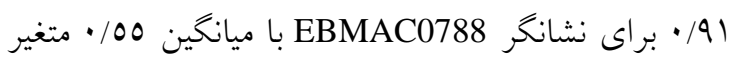

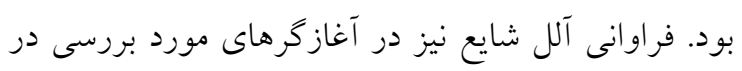

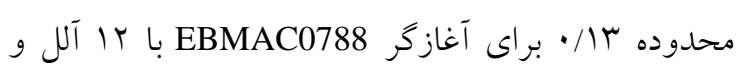

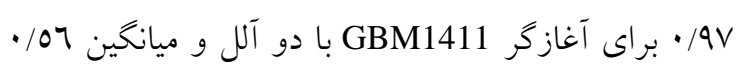
بهدست آمد. در بين نشانكرهاى مورد استفاده بيشترين

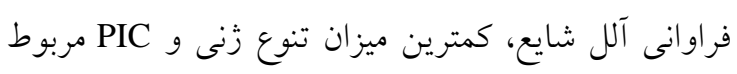

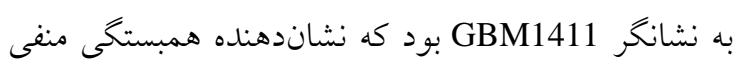

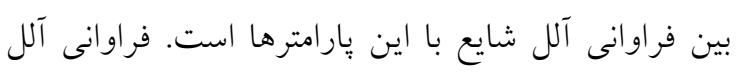

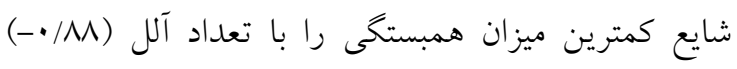

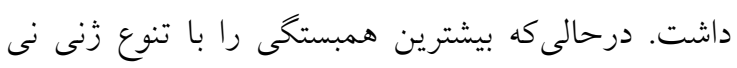

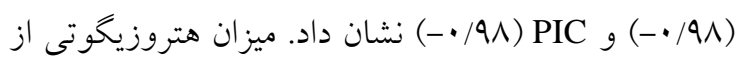

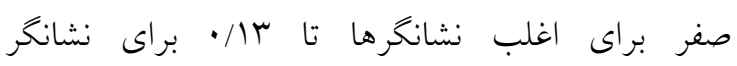

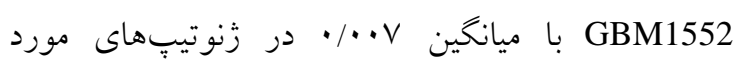
استفاده متغير بود.

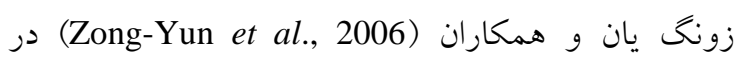

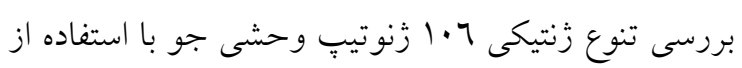

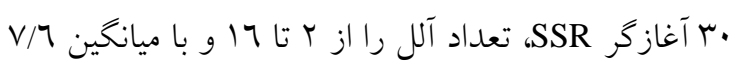

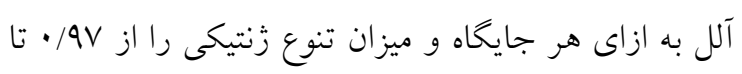

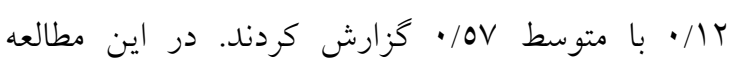

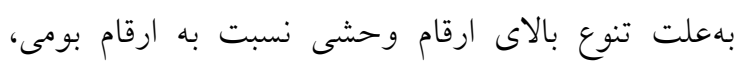

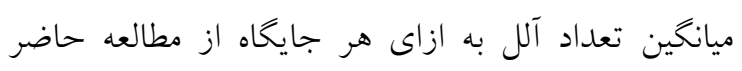

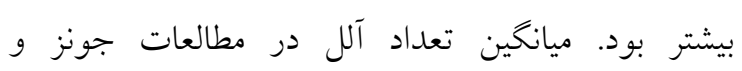

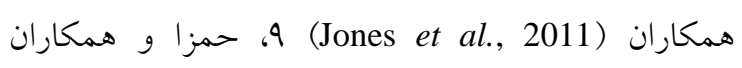
r/7 (Hamza et al., 2004) 10 (Yahiavi et al., 2008) ال ال بود. علت تفاوت در ميانخين (Pandey et al., 2004) تعداد آلل در مطالعات مختلف، بهدليل تفاوت در تعداد

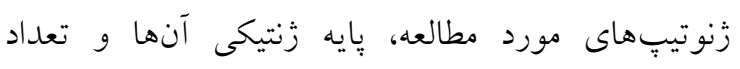


اصلاحى بودند. گروه II شامل 17 زنوتيٍٍ بومى ايران از

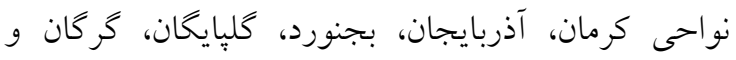

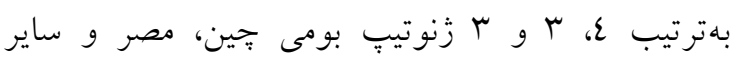

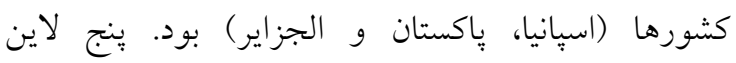
اصلاحى ييشرفته و سه رقم تجارى نيز در اين كروه قرار

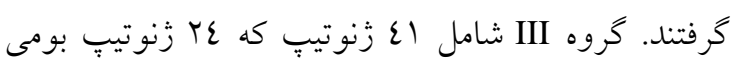

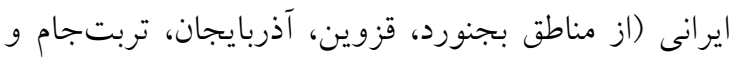

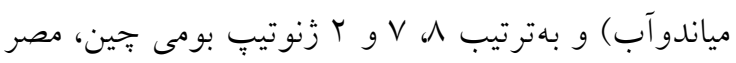

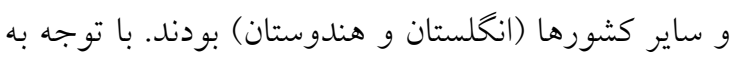
كروهبندى حاصل مشاهده مىشود كه بيشتر زنوتيبهاى بومى ايران و جين بهعلت تعلداد زياد و نيز تنوع اقليمى در لترد

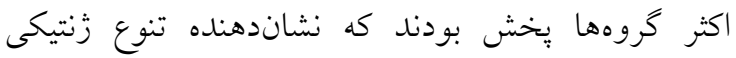
بسيار بالاى درون اين مناطق مىباشد. كاندمير و همكاران تنوع زنتيكى موجود در سه (Kandemir et al., 2010) كروه زنوتيب جو (زنوتيبهاى بومى، لاين خالص و ارقام

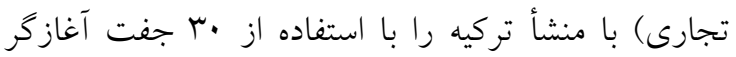
ريزماهواره مورد بررسى قرار دادند. با استفاده از •V آلل

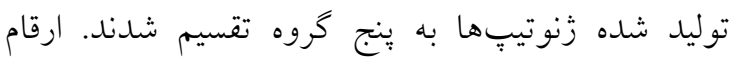

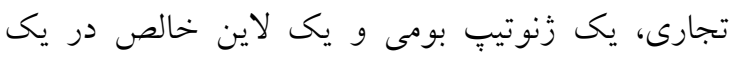

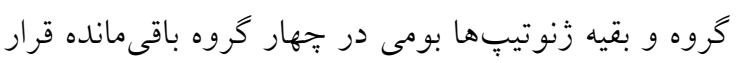

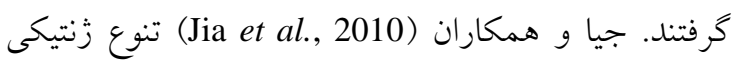

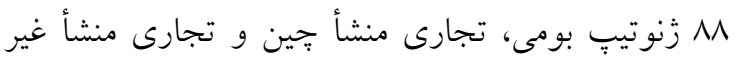

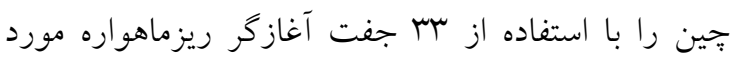
بررسى قرار دادند. نتايج حاصل از تجزيه گروهبندى با بان

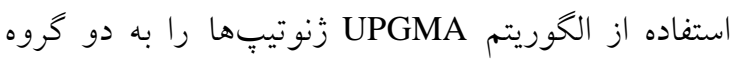
متتسب كرد بهطورى كه در حدود ·9 درصد از زنوتيب-

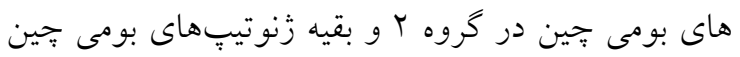

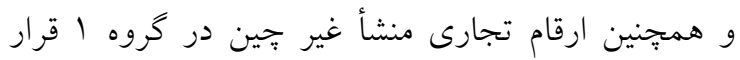
كرفتند. ليسوا و كوسرا (Lisova and Kucera, 2010) تنوع زنتيكى r Tr زنوتيبٍ دو رديفه و شش رديفه جو، شامل زنوتيٍها بومى، تجارى قديم و جديد، لاينهاى

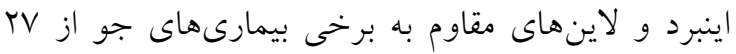

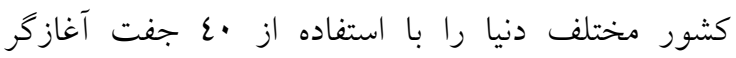

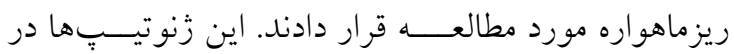

زنوتيٍ بومى جو از ·ل منطقه مختلف جغرافيايى اتيويى، بيشترين واريانس را در درون مناطق كزارش كردند. بآنها

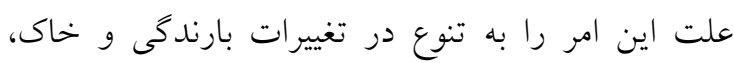

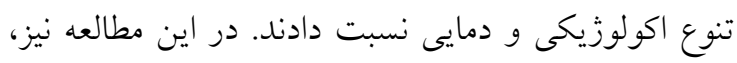

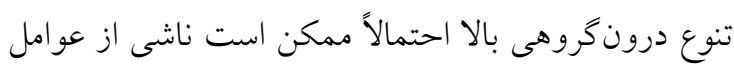

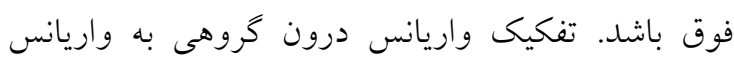

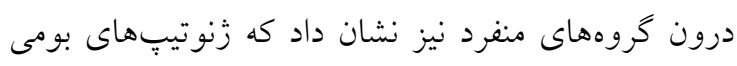

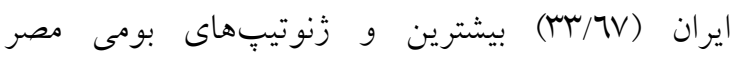

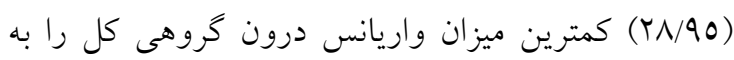
خود اختصاص دادند. همجنين بيشترين شاخص اطلاعات

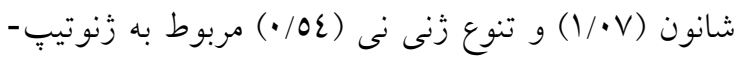
هاى بومى ايران و كمترين مقدار براى شاخص اطلاعات شانون (ع/N•) و تنوع زنى (1//•) مربوط به زنوتيبهاى

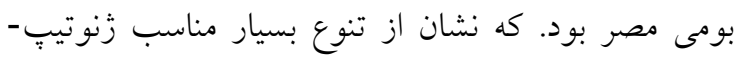

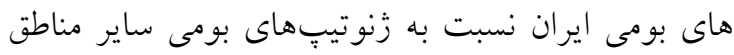
جغرافيايى در اين مطالعه بود. كنبر و و كاتسوهيكو (Kanbar and Katsuhiko, 2011)

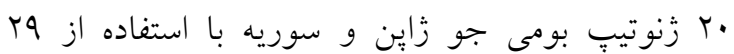

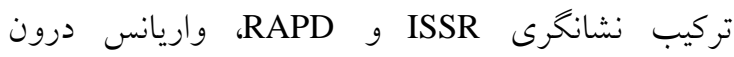
جمعيتى را در مجموع دادههاى اين دو نشانكر بالاتر (17)

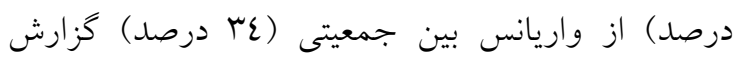

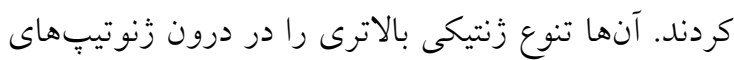

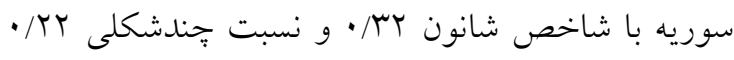
نسبت به زنوتيبها زاين مشاهده كردنا

كروهبندى زنوتيبٍ بها

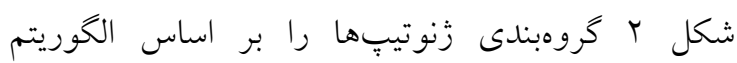
Minimum-Evolution استفاده از دادههاى SSR نشان مىدهد.برش دندروگرام بر اساس اعداد بوتاسترٍ و فاصله بين گروهها،

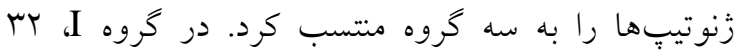

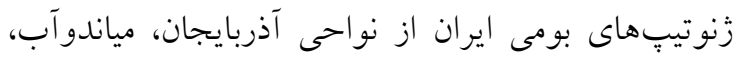

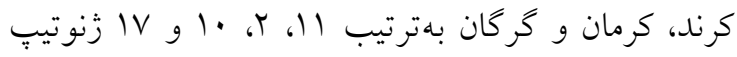
بومى جين، مصر، ساير كشورها (آمريكا، روسيه، اسيانيا،

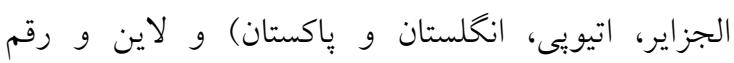




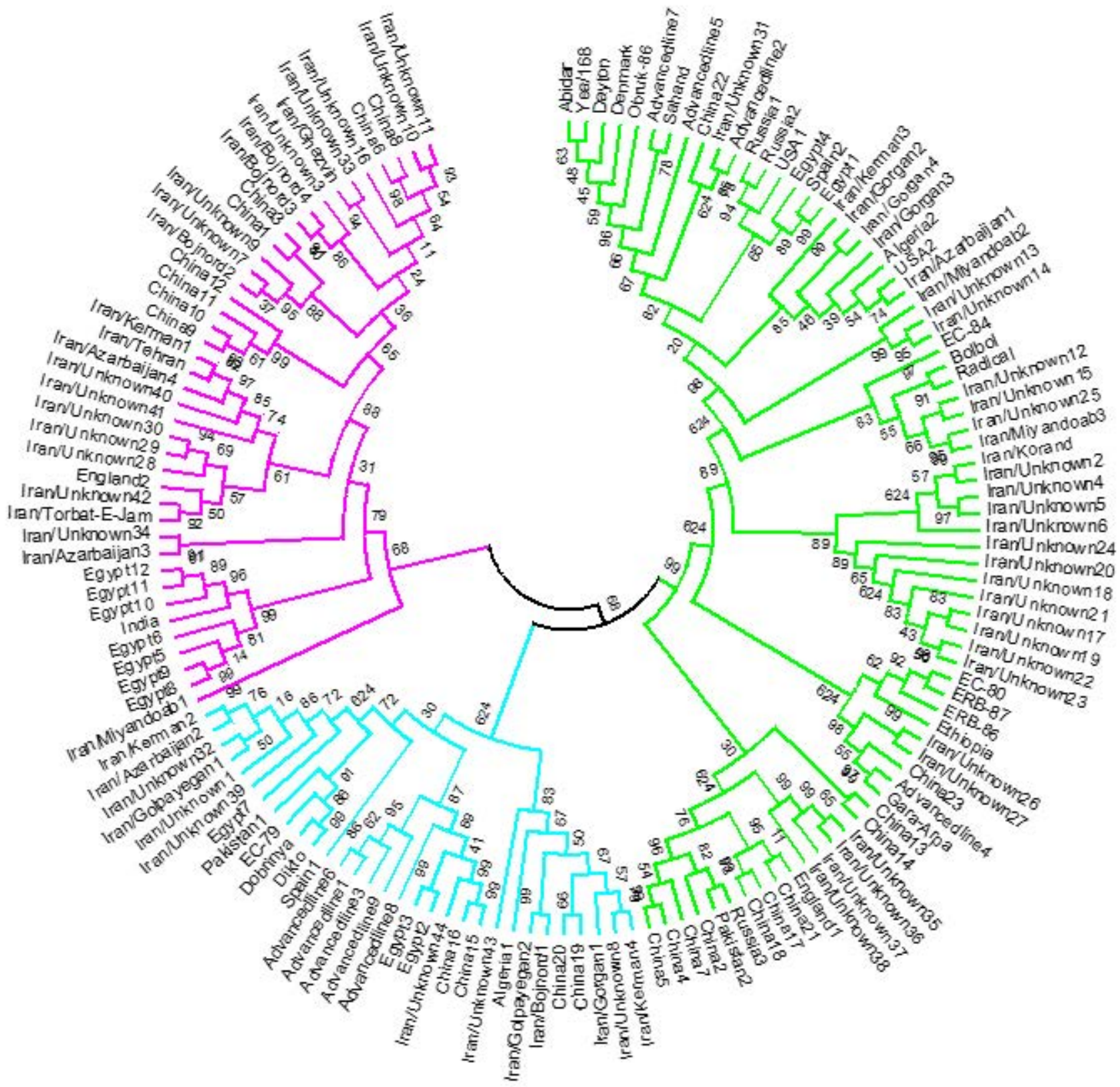

شكل r- كروهبندى زنوتيّهاى جو مورد مطالعه بر اساس دادههاى نشانكرهاى ريزماهو اره و با استفاده از الكوريتم

P-distance و ضريب فاصله Minimum Evolution

Figure 2. Grouping of the studied barley genotypes based on SSR marker data using the Minimum Evolution algorithm and P-distance coefficient

آنها اعلام داشتند كه الكوى گروهبندى با منشأ جغر افيايى Hamza et ) زنوتيبها مطابقت ندارد. حمزا و همكاران (al., 2004

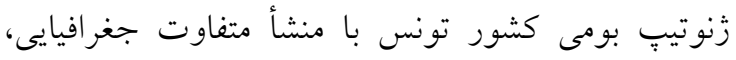

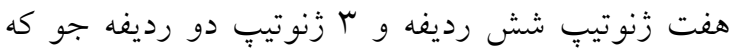

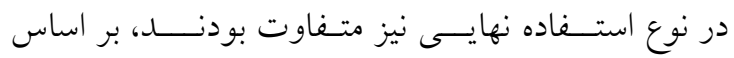

$$
\begin{aligned}
& \text { تجزيه خوشهاى به شش كروه منتسب شدند يك گروه } \\
& \text { فقط شامل زنوتيڤها دورديفه بود، بقيه زنوتيِها }
\end{aligned}
$$

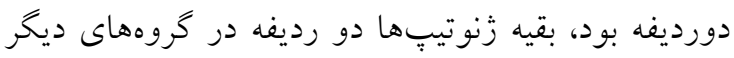

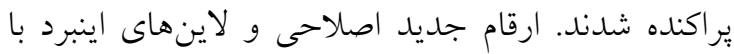

$$
\begin{aligned}
& \text { هم در دو گروه قرار گرفتند در حالى كه بقيه زنوتيبها } \\
& \text { بومى و تجارى قديم با هم در ساير كروهها قرار گرفتند. }
\end{aligned}
$$


در تجزيه بهبردارهاى اصلى سه بردار اصلى اول بهترتيب

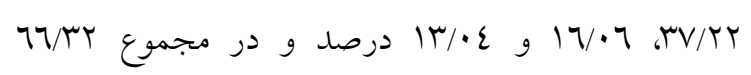
درصد تغييرات مولكولى كل را تبيين كردند. تبيين حدود 77 درصد تغييرات مولكولى كل توسط سه بردار اول

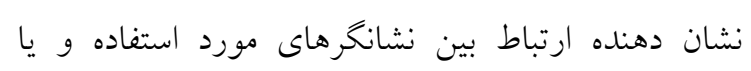

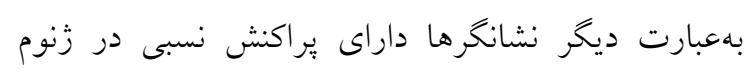

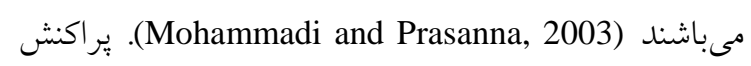
افراد بر اساس دو بردار اول در شكل r نشان داده شده

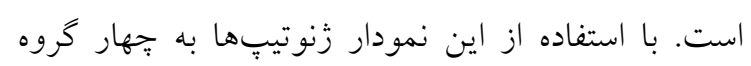

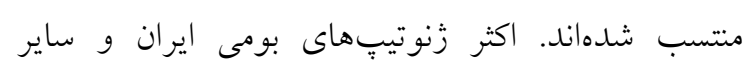

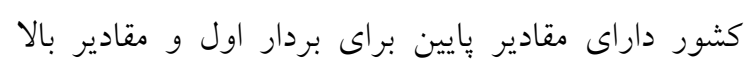

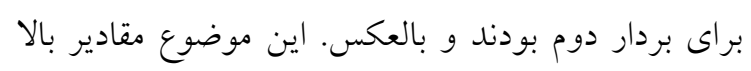

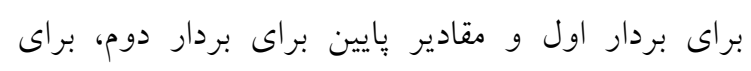

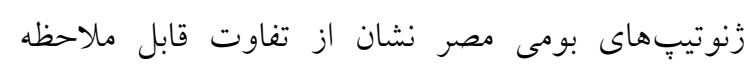

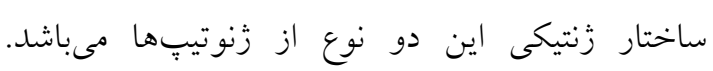

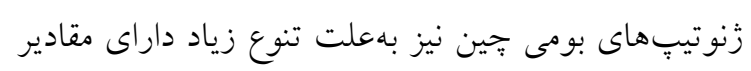

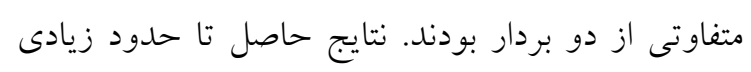
با نتايج تجزيه خوشهاى مطابقت داشت. جيا و همكاران

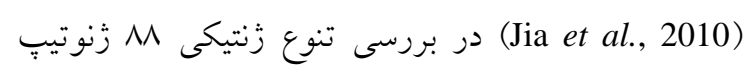

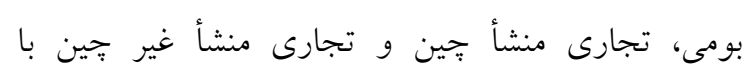

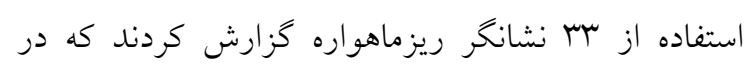

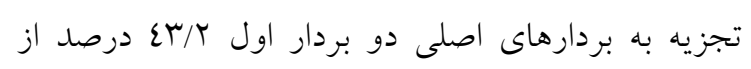

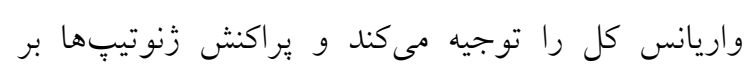

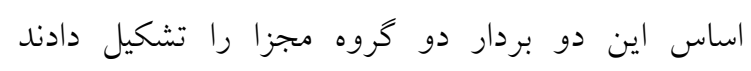

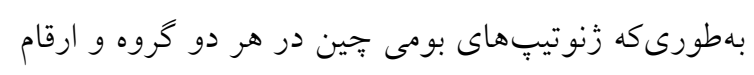

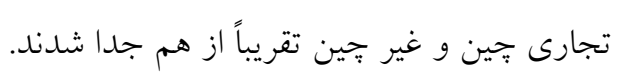

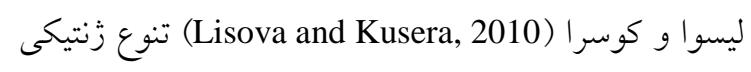

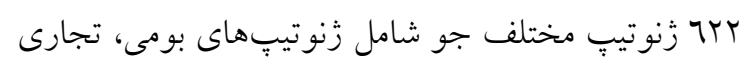

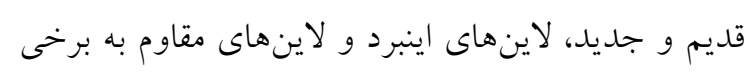

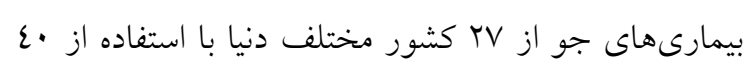
جفت آغازكر ريزماهواره مورد ارزيابى قرار دادند. تجزيه

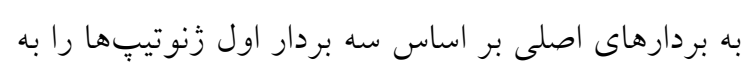

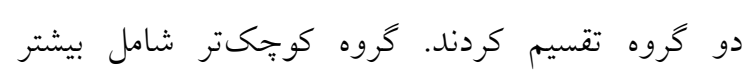

الخوريتم UPGMA، در نقطه برش دندروگرام، جهار گروه

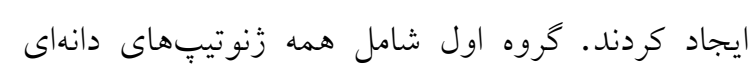

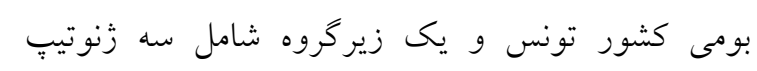

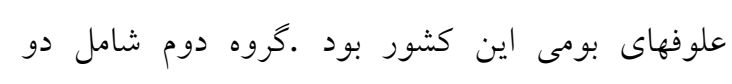

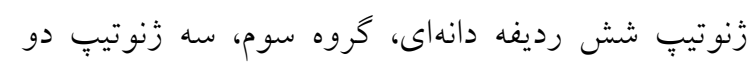

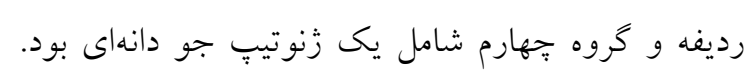

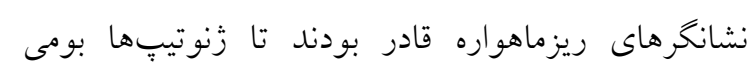

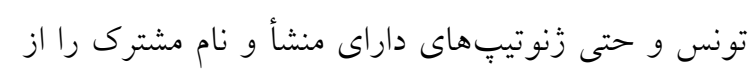

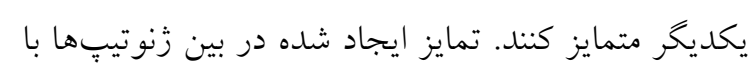

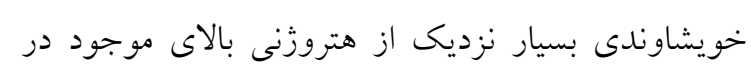

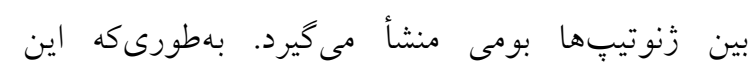

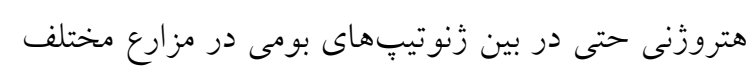
يكى منطقه (يكى زنوتيبٍ محلى) كه به يكى نام يكسان

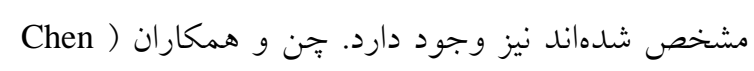
عدم مطابقت الكوى گروهبندى با منشأ (et al., 2012 جغرافيايى در تجزيه كلاستر، مىتواند دو دليل داشته

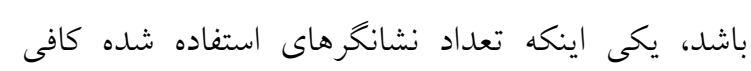

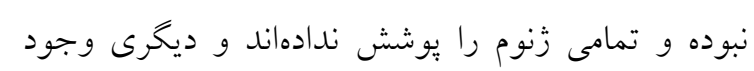

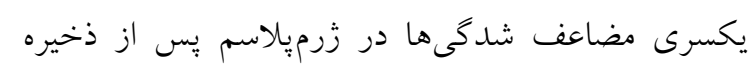

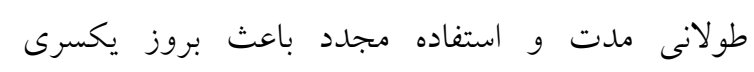

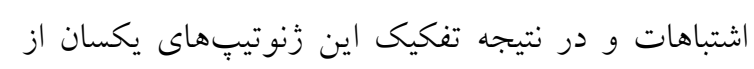

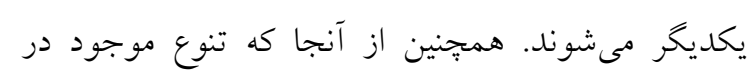
ارقام بومى تحت تأثير گزينش طبيعى (كزينش تحت تأثير

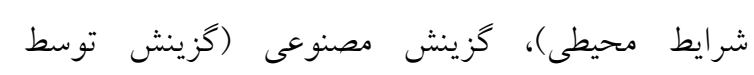
كشاورز) و جهش قرار مى گيرد، در نتيجه تفكيك ايجاد

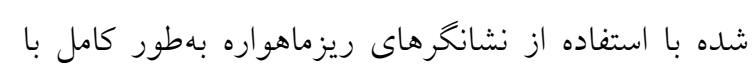

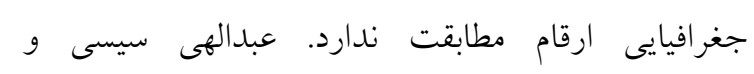
همكاران (Abodolahi sisi et al., 2012) نيز عدم قرار

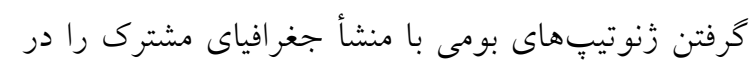

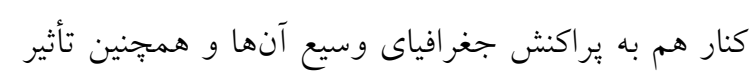
نيروهاى تكاملى متفاوت بر ساختار زنتيكى آنها اظهار داشتند. تجزيه به بردارهاى اصلى دانئ 


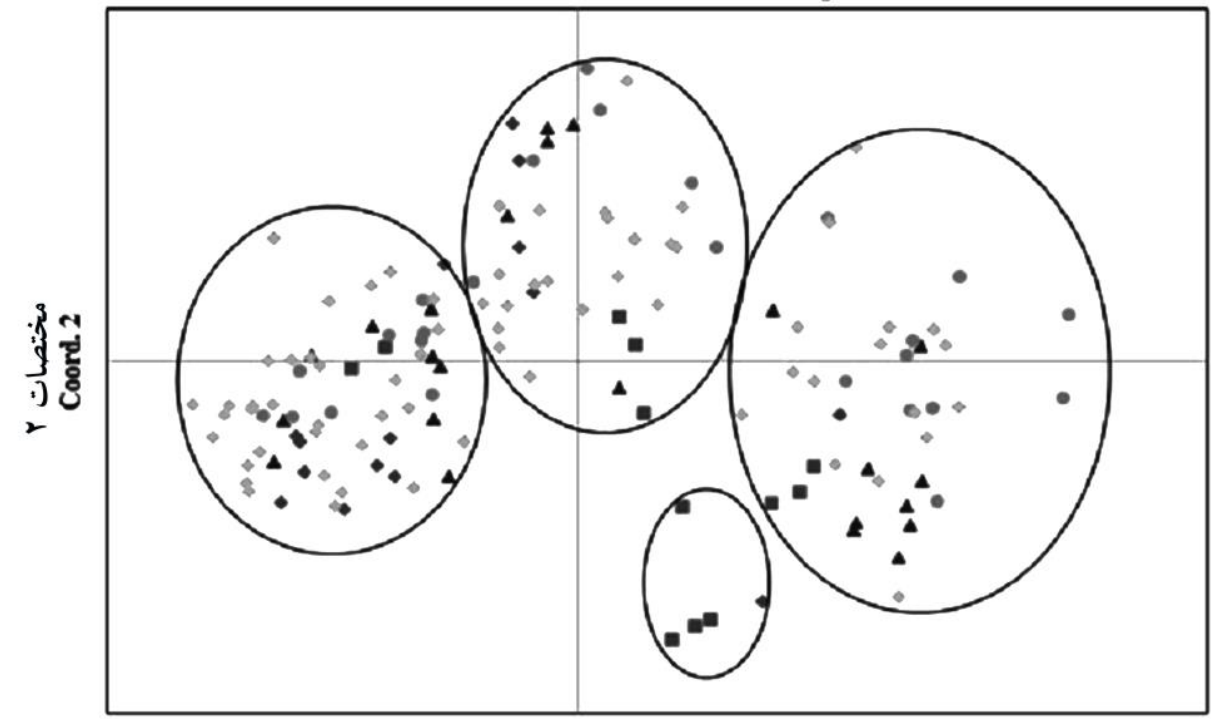

ثنوتيبهاى بومى ساير كثودها

Landrace of other countries

- ثنوتيبهاى بومى مصر

Egyptian local genotypes

ثنونيب هاى بومى جين

China local genotypes

ثنتيبهاى اصلاحى ـ

Improved genotypes

ثنوتيبهاى بومى ايران

Iranian local genotypes

Coord. 1

مختصات 1 ماء

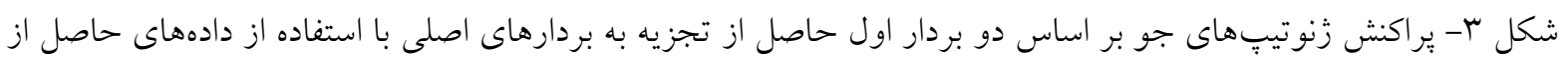
نشانخرهاى ريزماهواره

Figure 3. Distribution of barley genotypes based on two principal coordinates resulted from principal coordinate analysis, using microsatellite data

$$
\begin{aligned}
& \text { قابلتوجه بود كه با توجه به ارزشمندى اين ارقام، مىتوان } \\
& \text { زنوتيڤهاى بهاره و تعدادى از ارقام تجارى قديم و } \\
& \text { از اينها براى ايجاد جمعيتهاى بايه اصلاحى استفاده } \\
& \text { لاينهاى خالص بود و گروه بزرگتر شامل بيشتر } \\
& \text { كرد و اخر تنوع در برخى صفات در اين ارقام موجود نبود } \\
& \text { زُنوتيٍهاى زمستانى و برخى از زنوتيِهاى مقاوم به } \\
& \text { مىتوان از ارقام بومى براى جبران اين كمبود استفاده كرد. } \\
& \text { بيمارىها بود. اين مطالعه نشان داد كه نشانكرهاى } \\
& \text { سياسگزارى } \\
& \text { ريزماهواره مىتوانند بهعنوان ابزار مناسبى براى بررسى } \\
& \text { بدينوسيله از موسسه تحقيقات ديم كشور و بانك زن } \\
& \text { كياهى موسسه تحقيقات اصلاح و تهيه نهال و بذر كشور } \\
& \text { براى فراهم كردن مواد كياهى قدردانى مىشود. اين تحقيق } \\
& \text { با حمايت مالى قطب علمى اصلاح مولكولى غلات }
\end{aligned}
$$

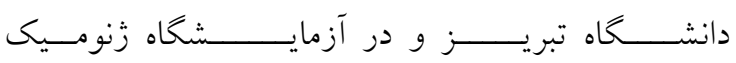

$$
\begin{aligned}
& \text { و اصــلاحنبــاتات مـــــلكولى دانشعاه تبريز انجام شد. } \\
& \text { تنوع زنتيكى زرميلاسمها بهكار روند. در اين تحقيق } \\
& \text { جفت آغازگر جندشكلى قابل قبولى را در ارقام مورد } \\
& \text { مطالعه ايجاد كردند. نتايج آزمايش نشان داد كه تنوع بسيار } \\
& \text { بالايى در درون ارقام بومى بخصوص زنوتيِهاى بومى } \\
& \text { ايران وجود دارد كه مىتوان از اين تنوع براى انجام } \\
& \text { برنامههاى اصلاحى مختلف استفاده كرد. تنوع زنتيكى } \\
& \text { موجود در بين ارقام تجارى و لاينهاى اصلاحى نيز }
\end{aligned}
$$

\section{References}

Abdollahi-Sisi, N., Mohammadi, S.M., Alavi-kia, S.S. and Sadeghzadeh, B. (2012). Efficiency of EST-SSR markers in determination genetic diversity and relationships of barley landraces. Cereal Research, 93:123- 133.

Abede, T.D., Mathew, B. and Le'on, J. (2013). Barrier analysis detected genetic discontinuity among Ethiopian barley (Hordeum vulgare L.) landraces due to landscape and human mobility on 
gene flowGenet Genetic Resources and Crop Evolution, 60: 297-309.

Botstein, D., White, R.L., Skolnick, M. and Davis, R.W. (1980). Construction of a genetic linkage map in man using restriction fragment length polymorphisms. American Journal of Human Genetics, 32: 314-331.

Brush, S. and Meng, E. (1998). Farmer's valuation and conservation of crop genetic resources. Genetic Resources and Crop Evolution, 45: 139-150.

Chen, Z.W., Lu, R.J., Zou, L., Du, Z.Z., Gao, R.H., He, T. and Huang, J.H. (2012). Genetic diversity analysis of barley landraces and cultivars in the Shanghai region of China. Genetic and Molecular Researche, 11: 644-650.

Condon, F., Charles-Gustus, D., Rasmusson, C. and Kevi, D.S. (2008). Effect of advanced cycle breeding on genetic diversity in barley breeding germplasm Crop Science, 48: 1027-1036.

Ebrahimi, A., Naghavi, M.R., Sabokdast, M. and Mardi, M. (2010). Assessment of genetic diversity in two accessions of barely species $(H$. vulgare L. and $H$. pontaneum L.) using SSR markers. Iranian Journal of Crop Sciences, 12: 333- 345 (In Persian).

Excoffier, L., Smouse, P. and Quattro, J.M. (1992). Analysis of molecular variance inferred from metric distances among DNA haplotypes: application to human mitochondrial DNA restriction data. Genetics, 131: 479-491.

FAO. (2013). FAO Statistical Database (FAOSTAT), Web site at URL: http://www.faostat.fao.org, Accessed 18 July 2013.

Ganjekhanloo, A., Mohammadi, S.A., Moghaddam, M., Shakiba, M.R., Ghasemi-Golezani, K. and Yousefi, A. (2012). Genetic diversity in barley as revealed by microsatellite markers and association analysis of these markers by traits related to freezing tolerance. Seed and Plant Improvment Journal, 28: 101-114 (In Persian).

Gong, X., Westcott, S., Li, C., Yan, G., Lance, R. and Sun, D. (2009). Comparative analysis of genetic diversity between Qinghai-Tibetan wild and Chinese landrace barley. Genome, 52: 849861.

Hamza, S., Hamida, W.B., Rebai, A. and Harrabi, M. (2004). SSR-based genetic diversity assessment among Tunisian winter barley and relationship with morphological traits. Euphytica, 135: $107-118$.

Heidari, A., Mohammadi, S.A., Moghaddam, M., Shakiba, M.R., Ghasemi-Golezani, K. and Yousefi, A. (2011). Analysis of genetic diversity in barley genotypes using SSR and EST-SSR markers Iranian Journal of Crop Sciences, 13: 146-156 (In Persian).

Ivandic, V., Hackett, C.A., Nevo, E., Keith, R., Thomas, W.T. and Forster, B.P. (2002). Analysis of simple sequence repeats (SSRs) in wild barley from the Fertile Crescent: associations with ecology, geography and flowering time. Plant Molecular Biology, 48: 511-527.

Jia, Q.J., Zhu, J.H., Wang, J.M. and Yang, J.M. (2010). Fusarium head blight evaluation and genetic diversity assessment by simple sequence repeats in 88 barley cultivars and landraces. In: Proceedings of the $10^{\text {th }}$ International Barley Genetics Symposium (Ceccarelli, S. and Grando, S., Eds.) PP. 298-311, ICARDA, Aleppo, Syria.

Jones, H., Civáň, P., Cockram, J., Leigh, F.J., Smith, L.M.J., Jones, M.K., Charles, M.P., Molina-Cano, J., Powell, W., Jones, G. and Brown, T.A. (2011). Evolutionary history of barley cultivation in Europe revealed by genetic analysis of extant landraces. B. M. C. Evolutionary Biology, 11: 320-332.

Joshi, S.P., Ranjekar, P.K. and Gupta, V.S. (1999). Molecular markers in plant genome analysis. Current Science, 77: 230-240.

Kadri, K., Abdellawi, R. and Cheikh-Mhamed, H. (2009). Genetic diversity in local Tunisian 
barley based on RAPD and SSR analysis. Biological Diversity and Conservatio, 2: 27-35.

Kanbar, A. and Katsuhiko, K. (2011). Efficiency of ISSR and RAPD dominant markers in assessing genetic diversity among Japanese and Syrian cultivars of barley (H. vulgare L.). Research Journal of Agriculture and Biological Sciences, 7: 4-10.

Kandemir, N., Yildirim, A. and Gunduz, R. (2010). Determining the levels of genetic variation using SSR markers in three Turkish barley materials known as Tokak. Turkish Journal of Agriculture and Forestry, 34: 17-23.

Karim, K., Rawda, A. and Hatem, C. (2010). Genetic diversity in Tunisian local barley based on RAPD and SSR analysis. African Journal of Biotechnology, 9(44): 7429-7436.

Leišová, L. and Kučera, L. (2010). The use of microsatellites to screen barley genotypes for resistance to net blotch. In: Proceedings of the 10th International Barley Genetics Symposium, Eds. Ceccarelli, S. and Grando, S, PP. 298-311. ICARDA, Aleppo, Syria

Liu, K. and Muse, S.V. (2005). Power Marker: an integrated analysis environment for genetic marker data. Bioinformatics, 21: 2128-2129.

Mango, T., Carrierosu, F., Cifavell, R.A., Gallitelli, M. and Callini, F. (2001). Development of microsatellite markers in durum wheat (Triticum turgidum L. ssp durum). Chinese Journal of Genetics, 33: 917-928.

Matus, I.A. and Hayes, P.M. (2002). Genetic diversity in three groups of barley germplasm assessed by simple sequence repeats. Genome, 45: 1095-1106.

Mohammadi, S.A. and Prasanna, B.M. (2003). Analysis of genetic diversity in crop plants salient statistical tools and considerations. Crop Science, 43: 1235-1248.

Nei, M. (1973). Analysis of gene diversity in subdivided populations. Proceedings of the National Academy of Sciences of the United States of America, 70: 3321-3323.

Pandey, M.P., Wagner, C., Friedt, W. and Ordan, F. (2004). Assessment of genetic diversity of hull-less barley germplasm in the high altitude Himalayas of Nepal. Theoretical and Applied Genetics, 113: 715-729.

Peakall, R. and Smouse, P.E. (2006). GENALEX 6.4: Genetic analysis in Excel: population genetic software for teaching and research. Molecular Ecology Notes, 6: 288-295.

Pillen, K., Binder, A., Kreuzkam, B., Ramsay, L., Waugh, R., Förster, J. and Léon, J. (2000). Mapping new EMBL-derived barley microsatellites and their use in differentiating German barley cultivars. Theoretical and Applied Genetics, 101: 652-660.

Saghai Maroof, M.A., Solaiman, K., Tprgensen, R.A. and Allard, R.W. (1984). Ribosomal DNA spacer-lenth polymorphism in barely: Mendelian inheritance, chromosomal location and population dynamics. Proceedings of the National Academy of Sciences of the United States of America, 81: 8014-8018.

Stam, B.K., Bothmer, A., Dayteg, R., Rashal, C., Tuvesson, S. and Weibullj, S. (2007). Genetic diversity changes and relationships in spring barley germplasm of Nordic and Baltic areas as shown by SSR markers. Genetic Resources and Crop Evolution, 16: 749-758.

Tamura, K., Dudley, J., Nei, M. and Kumar, S. (2011). MEGA 5: molecular evolutionary genetics analysis (MEGA) software, version 5.0. Molecular Biologyand Evolution, 24: 1596-1599.

Wang, M.L., Barkley, N.A., Yu, J.K., Dean, R.E., Newman, M.L., Sorrells, M.E. and Pederson, G.A. (2005). Transfer of simple sequence repeat (SSR) markers from major cereal crops to minor grass species for germplasm characterization and evaluation. Plant Genetic Resources, 3: 45-57.

Yahiavi, S., Igartua, E., Moralejo, M., Ramsay, L., Molina-Cano, J.L., Ciudad, F.J., Lasa, J.M., Gracia, M.P. and Casas, A.M. (2008). Patterns of genetic and eco-geographical diversity in Spanish barleys. Theoretical and Applied Genetics, 116: 271-282. 
ئزوهشهاى زنتيك گياهى / جلد / / شماره |

Yeh, F.C., Yang, R.C. Boyle, T.B.J., Ye, Z.H. and Mao, J.X. (1997). POPGENE, the User-Friendly Shareware for Population Genetic Analysis. Molecular Biology and Biotechnology Centre. University of Alberta, Canada.

Zhu, J., Gale, M.D., Quarrie S., Jackson, M.T. and Bryan, G.J. (1998). AFLP markers for the study of rice biodiversity. Theoretical and Applied Genetics, 96: 602-611.

Zoghlami, N., Bouagila, A., Lamine, M., Hajri, H. and Ghorbel, A. (2012). Population genetic structure analysis in endangered Hordeum vulgare L. landraces from Tunisia: conservation strategies. African Journal of Biotechnology, 10: 10344-10351.

Zong-Yun, F., Xian-Jun, L., Yi-Zheng, Z. and Hong-Qing, L. (2006). Genetic diversity analysis of Tibetan wild barley using SSR markers. Acta Genetica Sinica, 33: 917-928. 


\title{
Molecular Analysis of Genetic Diversity and Relationships of Barley Landraces Based on Microsatellite Markers
}

\author{
Ali Shuorvazdi ${ }^{1}$, Seyed Abuolghasem Mohammadi',3,*, Majid Norozi ${ }^{4}$ and Behzad \\ Sadeghzadeh $^{5}$ \\ 1- Former M.Sc. Student, Department of Plant Breeding and Biotechnology, University of \\ Tabriz, Tabriz, Iran \\ 2- Professor, Department of Plant Breeding and Biotechnology, University of Tabriz, Tabriz, \\ Iran \\ 3- Center of Excellence in Cereal Molecular Breeding, University of Tabriz, Tabriz, Iran \\ 4- Assistant Professor, Department of Plant Breeding and Biotechnology, University of \\ Tabriz, Tabriz, Iran \\ 5- Assistant Professor, Dryland Agriculture Research Institute of Iran, Maragheh, Iran
}

(Received: November 10, 2013 - Accepted: February 3, 2014)

\begin{abstract}
Due to their adaptation to different environment conditions, landraces are valuable genetic resurces for incresing diversity of breeding germplasms and are potential resources for biotic and abiotic stress resistant genes. In the present study, genetic diversity and relationships of 119 barely landraces from different countries along with 25 commerical varieties and breeding lines were assessed, using 45 microsatellite primer pairs. In total, 225 alleles range from 2 to 14 and an average of 5 alleles per locus were amplified. Polymorphic information contenet (PIC) varied from 0.05 to 0.90 with a mean of 0.51 . The minimum and maximum frequency of common allele belonged to EBMAC0788 (0.13) and GBM1411 (0.97) markers, respectively. Analysis of molecular variance (AMOVA) revealed a higher within group variation (94\%) than between group. Maximum and minimum Shannon's and Nei gene diversity indices were observed in Iranian and Egyptian landraces, respectively. Cluster analysis using Minimum Evolution algorithm and P-distance coefficient assigned the studied genotypes into three groups. This grouping was partly consistent with geographical origins of the genotypes.
\end{abstract}

Keywords: Genetic diversity, Germplasms, Barley landraces, Population structure

\footnotetext{
* Corresponding Author, E-mail: mohammadi@ tabrizu.ac.ir
} 